Title:

NDA ISSUES WITH RFETS VITRIFIED WASTE FROMS
Author(s):

Submitted to:
Jon Hurd and Gerry Veazey

\section{DISTRESTION OF THIS DOCUMENT is UREMURE ph}

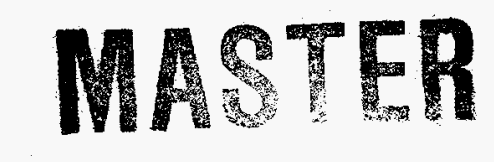

RFETS as a final report on project

\section{Los Alamos} NATIONAL LABORATORY
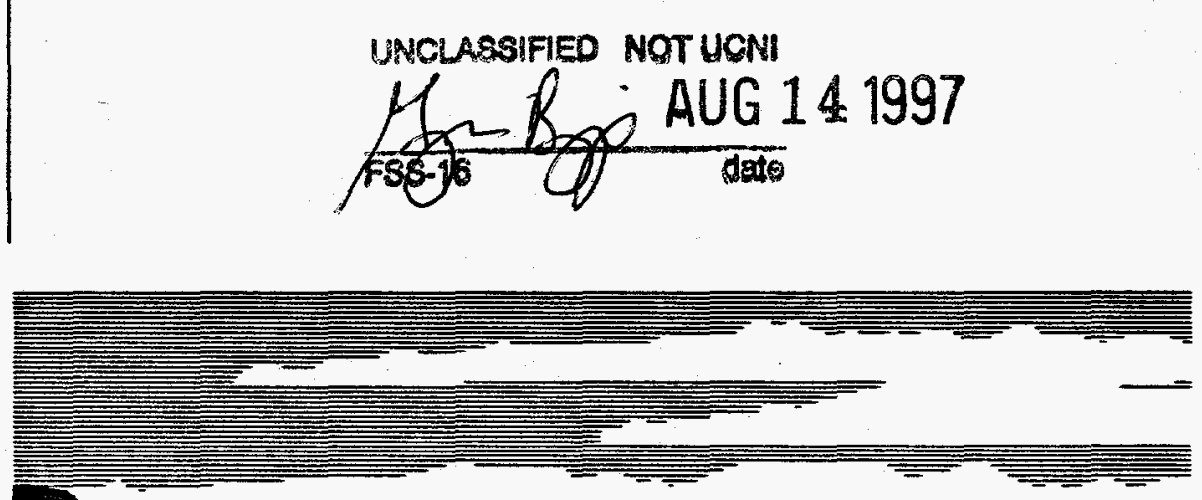

Los Alamos National Laboratory, an affirmative actionvequal oppontunity employer, ts operated by the University of Califomia for the U.S. Department of Energy under contract W.7405-ENG-36. By acceptance of this article, the publisher recognizes that the U.S. Government retains a nonexclusive, royalty-free license to publish or reproduce the published form of this contribution, or to allow others to do so, for U.S. Government purposes. The Los Alamos National Laboratory requests that the publisher identify this articte as work pertormed under the auspices of the U.S. Deparment of Energy. 


\section{DISCLAIMER}

This report was prepared as an account of work sponsored by an agency of the United States Government. Neither the United States Government nor any agency thereof, nor any of their employees, makes any warranty, express or implied, or assumes any legal liability or responsibility for the accuracy, completeness, or usefulness of any information, apparatus, product, or process disclosed, or represents that its use would not infringe privately owned rights. Reference herein to any specific commercial product, process, or service by trade name, trademark, manufacturer, or otherwise does not necessarily constitute or imply its endorsement, recommendation, or favoring by the United States Government or any agency thereof. The views and opinions of authors expressed herein do not necessarily state or reflect those of the United States Government or any agency thereof. 


\section{DISCLAMVIR}

Portions of this doeconent my be illegible in electronic ironge products. Images are produed from the best available origion docemenert 


\title{
NDA ISSUES WITH RFETS VITRIFIED WASTE FORMS
}

\author{
by \\ Jon Hurd and Gerry Veazey \\ Los Alamos National Laboratory
}

\section{EXECUTIVE SUMMARY}

A study was conducted at Los Alamos National Laboratory (LANL) for the purpose of determining the feasibility of using a segmented gamma scanner (SGS) to accurately perform nondestructive analysis (NDA) on certain Rocky Flats Environmental Technology Site (RFETS) vitrified waste samples. This study was performed on a full-scale vitrified ash sample prepared at LANL according to a procedure similar to that anticipated to be used at RFETS. This sample was composed of a borosilicate-based glass frit, blended with ash to produce a Pu content of $\sim 1 \mathrm{wt} \%$. The glass frit was taken to a degree of melting necessary to achieve a full encapsulation of the ash material. The NDA study performed on this sample showed that SGSs with either $1 / 2$ - or 2 -inch collimation can achieve an accuracy better than $6 \%$ relative to calorimetry and $\gamma$-ray isotopics. This accuracy is achievable, after application of appropriate bias corrections, for transmissions of about $1 / 2 \%$ through the waste form and counting times of less than 30 minutes. These results are valid for ash material and graphite fines with the same degree of plutonium particle size, homogeneity, sample density, and sample geometry as the waste form used to obtain the results in this study. A drum-sized thermal neutron counter (TNC) was also included in the study to provide an alternative in the event the SGS failed to meet the required level of accuracy. The preliminary indications are that this method will also achieve the required accuracy with counting times of $\sim 30$ minutes and appropriate application of bias corrections. The bias corrections can be avoided in all cases if the instruments are calibrated on standards matching the items.

\section{INTRODUCTION}

Vitrification is currently being investigated as the rebaseline technology for the treatment of several 94-1 materials at RFETS. The materials being considered for vitrification are those contained in the ash residue bucket category, which includes low-fired ash, graphite fines, and sand, slag, and crucible (SS\&C). The project to develop a vitrification process for these materials includes three sub-projects: 1) development of a glass-frit formulation(s) for the residues, 2) development of a process flow sheet for implementation of the vitrification technology at RFETS, and 3) determination of an NDA technique for the analysis of the final vitrified waste form. It was considered imperative that the sub-projects be designed to be compatible with

\footnotetext{
* Vitrification is technically used to describe the process that produces an amorphous, molecularlyhomogeneous product in which the material being treated becomes dissolved in the glass matrix. The final waste form for this project is intended to result only in the encapsulation of the treated material. Encapsulation results in the material being surrounded by the glass matrix without dissolution of the treated material.
} 
existing equipment at RFETS. This dictated that the vitrified waste form be produced with a conventional muffle furnace and an SGS with a $1 / 2$-inch collimator be used as the NDA technique. This report describes the results of the study to investigate the feasibility of utilizing SGS technology to determine the Special Nuclear Material (SNM) content of the vitrified waste form as produced with a conventional muffle furnace.

The specific objective of this study was to determine if the SGS could meet an accuracy criterion of no more than a $10 \%$ difference in the SNM content as measured by an accurate baseline method such as calorimetry and $\gamma$-ray isotopics. The study focused on several factors known to decrease the accuracy of the SGS technique: sample density and homogeneity, end effects, and lump (self-attenuation) effects. These factors (discussed below) were studied through the analysis of an actinide-containing sample prepared to mimic the projected glass-based RFETS waste form. A drum-sized TNC was also included in the investigation to provide an alternative in the event the SGS failed to meet the required level of accuracy.

\section{SAMPLE PREPARATION}

A full-scale sample was prepared using processing techniques as similar as possible to those anticipated at RFETS for encapsulating ash material in a glass-based matrix. At the time this experiment was conducted, the RFETS ash waste form was anticipated to be produced by melting borosilicate-based glass frit to bring about encapsulation of the ash waste. The quantity of glass frit in each waste form was anticipated to be that required to blend the Pu content to $1 \mathrm{wt} \%$." The projected container was a stainless-steel Vollrath $\# 88080$ can with a thickness of $1 / 32$ inch, a diameter of 8 inches and a height of 10 inches.

RFETS ash from the TA-55 vault was used for preparation of the glass-based waste form. This ash was chosen to simulate the ash inventory at RFETS as closely as possible. The ash at RFETS was reported to have a Pu content of $\sim 5 \mathrm{wt} \%$ and a high carbon, chloride, and fluoride content due to incomplete combustion of the ash's organic component. The most similar ash item at TA55 that was available in sufficient quantity was an item (BARFAT2) with Pu content of $\sim 9 \mathrm{wt} \%$. This item had a loss-on-ignition value of $8.55 \%$, a density of $0.87 \mathrm{~g} / \mathrm{cm}^{3}$, and a particle size of minus 40 mesh. ${ }^{1}$ The elemental characterization of this ash is reported in Table 1.

During preliminary non-actinide tests at PNNL, two issues were uncovered that were addressed in the full-scale test at LANL. The first issue was that significant foaming occurred in the container after melting of the frit began due to off-gassing, presumably of the organic component in the ash. The surface of the material in the container rose by as much as $52 \%$ due to foaming. PNNL found that removing the organic by calcining at $\sim 500^{\circ} \mathrm{C}$ prior to

\footnotetext{
* Since the time of this project, the glass frit has been changed to a lower-melting phosphate-based one. In addition, the final waste form has been changed to one in which the temperature is raised only to that required to produce an agglomeration of the frit beads. This change was incorporated to address the foaming problem (discussed below) by maintaining open passages between the individual frit beads to allow for escape of the off-gasses responsible for foaming. Lastly, the target Pu content has been raised to $2 \mathrm{wt} \%$ to meet the safeguards termination limits.
} 
melting significantly reduced this foaming. To address this concern at LANL, the ash/frit blend was subjected to a slow temperature ramp-up to remove as much organic as possible prior to the melting process. In addition, the fill height in the container was reduced to prevent overflow due to foaming.

Table 1

Compositional Data on BARFAT2

\begin{tabular}{|c|c|c|c|c|c|}
\hline Element & $\begin{array}{c}\text { Concentration } \\
(\mathbf{w t} \%)\end{array}$ & Element & $\begin{array}{c}\text { Concentration } \\
\text { (wt \%) }\end{array}$ & Element & $\begin{array}{c}\text { Concentration } \\
\text { (wt \%) }\end{array}$ \\
\hline $\mathbf{P u}$ & 9.34 & $\mathbf{C u}$ & 1.2 & $\mathbf{N a}$ & 1.00 \\
\hline $\mathbf{A m}$ & 0.02 & $\mathbf{C r}$ & 0.92 & $\mathbf{N i}$ & 0.74 \\
\hline $\mathbf{A l}$ & 3.50 & $\mathbf{F e}$ & 9.40 & $\mathbf{P b}$ & 1.70 \\
\hline $\mathbf{B}$ & 0.14 & $\mathbf{F}$ & 2.09 & $\mathbf{S i}$ & 1.1 \\
\hline $\mathrm{Ba}$ & 0.63 & $\mathbf{K}$ & 7.80 & $\mathbf{T i}$ & 1.70 \\
\hline $\mathbf{C}$ & 0.28 & $\mathbf{M g}$ & 1.30 & $\mathbf{Z n}$ & 2.8 \\
\hline $\mathbf{C a}$ & 8.40 & $\mathbf{M n}$ & 0.37 & & \\
\hline $\mathbf{C l}$ & 11.09 & $\mathbf{M o}$ & 0.04 & & \\
\hline
\end{tabular}

The second issue identified at PNNL was that significant corrosion and deformation of the Vollrath container occurred at temperatures near $1100^{\circ} \mathrm{C}$. In a PNNL sample prepared at this temperature, a pin-hole-sized breach occurred in the container wall at the surface of the melt. In addition, bulging of the container by $\sim 1 / 4$ inch occurred at the surface of the melt. To address this concern at LANL, the melt container was modified by placing the Vollrath container inside another stainless steel container having a 1/16-inch thickness, 6 1/2-inch height, and $81 / 16$-inch diameter. In order to reduce container corrosion due to high temperature, a lower-temperature borosilicate-based frit was selected that could be melted at no greater than $1000^{\circ} \mathrm{C}$. The composition of this frit is shown in Appendix A.

The procedure used to produce the waste form at LANL for the NDA study is described in Appendix B. ${ }^{*}$ Several observations were made during and after the procedure. The final height of the melted material in the inner container was 2.6 inches, representing a $48 \%$ decrease in height from the initial height of 5 inches. No evidence of foaming (foam line) appeared in the container. The inside of the container wall experienced spalling, with the residue ending up on the surface of the melt as black flakes. However, the spalling was not enough to jeopardize container integrity. In addition, the surface contained several bright yellow patches. These patches are thought to be due to incomplete dissolution of impurities in the ash and/or frit." The inside of the container and surface of the waste form are shown in Figure 1. The completed sample was prepared for the NDA study by bagging out the melt container and placing it in an overpack. The overpack was a $\sim 1 / 16$-inch thick steel container with a diameter of 9.9 inches and a height of 12.2 inches.

\footnotetext{
For the study at LANL, the height of the container was reduced to 8 inches to fit within the LANL furnace used in the study.

\# The material may be chromate or sulfate. Chromate formation can be avoided by precipitating the chromium in the form of spinels.
} 


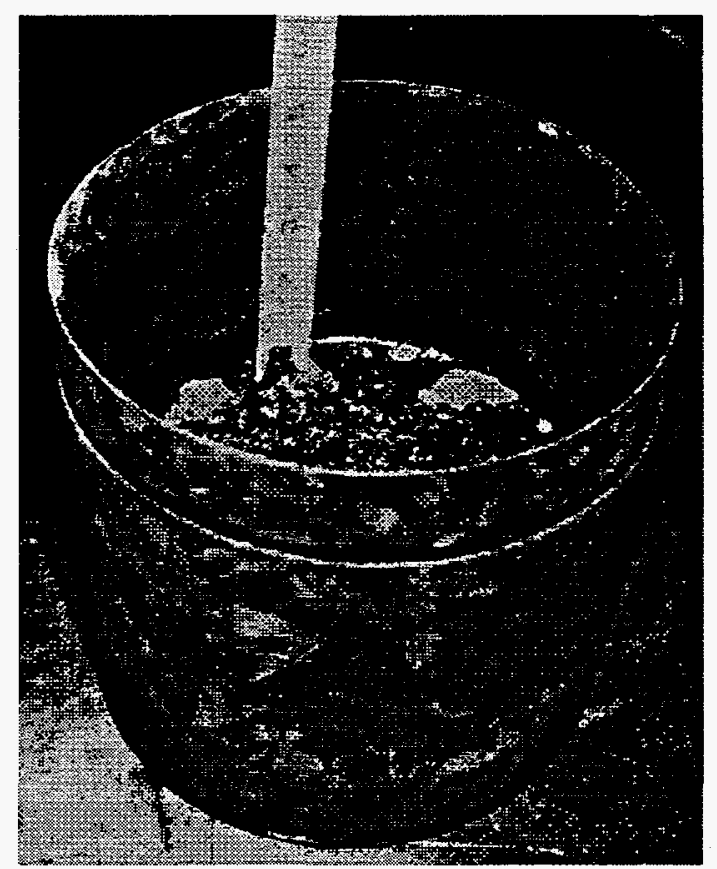

Figure 1. NDA sample

\section{SAMPLE MEASUREMENT AND ANALYSIS}

\section{Baseline Determination}

The first step in the measurement process was to establish the most accurate baseline SNM content for the vitrified ash sample as possible. This was accomplished by measuring with a calorimetry and $\gamma$-ray isotopics system since that technique is known to introduce little or no bias. ${ }^{2}$ The results are shown in Table 2.

Table 2

Calorimetry and Gamma Isotopics Data ${ }^{\dagger}$

\begin{tabular}{|c|c|c|c|c|c|c|}
\hline & Pu-238 & Pu-239 & Pu-240 & Pu-241 & Pu-242 & $\begin{array}{c}\text { Am-241 } \\
(\mu \mathrm{g} / \mathrm{g} \text { Pu })\end{array}$ \\
\hline Mass \% & 0.01082 & 93.65381 & 6.14144 & 0.16893 & 0.02500 & 2048.8 \\
\hline Sigma & 0.00132 & 0.21515 & 0.21560 & 0.00068 & 0.00125 & 32.2 \\
\hline Rel. Sigma & $12.10 \%$ & $0.23 \%$ & $3.51 \%$ & $0.40 \%$ & $4.98 \%$ & $1.54 \%$ \\
\hline
\end{tabular}

${ }^{\dagger}$ Specific power (watts/g-Pu) $=(2.54667+/-0.01789) \mathrm{E}-03(0.70 \%)$

Sample power of 0.14910 watts measured on $26-\mathrm{Feb}-97$.

Since the calorimetric uncertainty ${ }^{2}$ for this type of item is known to be $\leq 1 \%$ and since the uncertainty on the specific power is reported to be $0.70 \%$, the uncertainty on the total value $(58.547 \mathrm{~g})$ should be on the order of $1 \%$. The primary drawback to using this technique on 
many items of this nature (i.e., low gram loading of $\mathrm{Pu}$ and relatively low heat conductivity of glass) is the long time to achieve calorimetric equilibration (about 8 to 12 hours).

\section{SGS Measurement Issues}

The next step was to measure the sample with an SGS, the preferred method at RFETS, in order to establish the feasibility of this technique ${ }^{3}$ for the vitrified ash item described above and determine appropriate operating parameters and constraints. Two such instruments reside in the NDA Laboratory at Los Alamos, one with $1 / 2$-inch collimation used for can-sized items and the other with 2-inch collimation. The SGS with 2-inch collimation is typically used for measuring drums, although smaller items can also be measured with reasonable accuracy. These instruments determine the quantity of SNM present in a sample by measuring the $\gamma$ radiation emitted from the SNM and comparing the corrected count rate with that from a known calibration standard. Since the $\gamma$ rays are attenuated as a function of distance in traversing through the sample matrix, a correction factor must be applied. This factor is determined by using a $\gamma$-ray source of known strength (the transmission source) and measuring its absorption through the sample. ${ }^{4}$ The amount of absorption is a function of the sample density and uniformity. To help reduce the effects of matrix nonuniformity (or inhomogeneity), an averaging process is invoked by rotating and translating ${ }^{*}$ the sample during the measurement cycle. Data are therefore acquired for a number of horizontal slices spanning the sample height. These slices are summed at the end of the assay to obtain the total SNM content. If the sample is too dense or nonuniform to allow proper functioning of the transmission source, either the measurement uncertainties will be intolerably large or there will be no assay result at all.

A special case of transmission difficulty, known as "end effects," occurs during the measurement at the top and bottom of every sample. Figure 2 shows a situation for a particular segment where counts are received into the detector with no transmission correction. As seen in the figure, end effects arise because the transmission measurement at the ends of the container does not representatively survey the material that is producing the $\gamma$ radiation in that area. This is because the $\gamma$-ray acceptance cone from the detector collimator is larger for the sample than for the transmission source. These end effects are a special case of the more generalized uncertainties that arise when nonuniform (e.g., a bubble or any break, gap, or discontinuity in the matrix) items are measured. ${ }^{5}$ End effects can extend over a number of segments, depending on the instrument and sample geometry, and the result always biases the final answer low. The low bias occurs because the transmission source $\gamma$ rays suffer less attenuation than those from the SNM in the matrix, resulting in correction factors for the affected segments that are too small. The degree to which the end-effects phenomenon affects the final answer is dependent upon the sample height to collimator (and segment step size) ratio, since a taller sample has a smaller fraction of affected segments.

\footnotetext{
* Changing sample height to view different segments of the sample.
} 


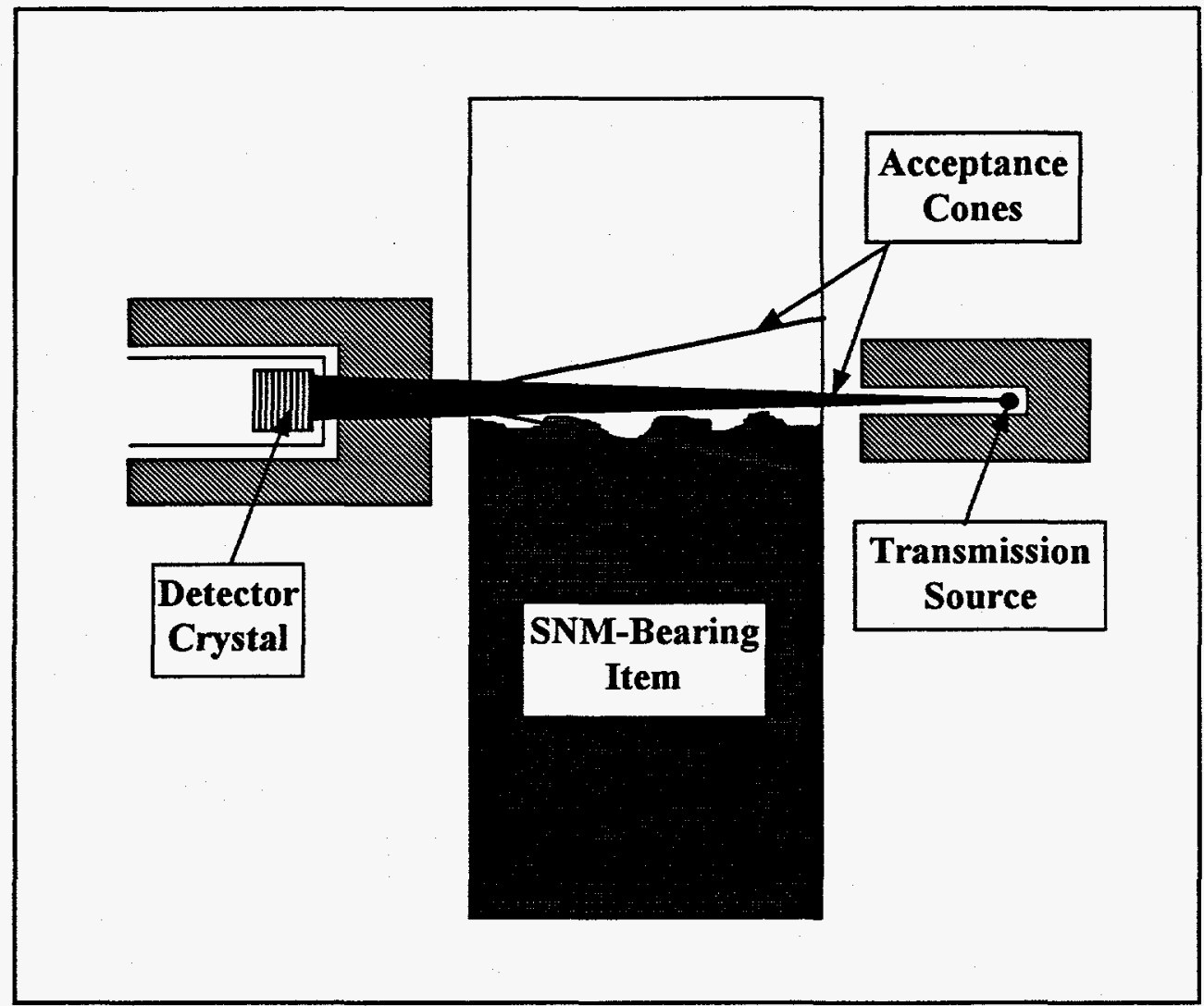

Figure 2. End Effects

One additional difficulty arises if the SNM (Pu in this case) is in the form of large particles or lumps of material. If the lump is of sufficient radius, then the $\gamma$ radiation would be attenuated enough while escaping the lump to generate a bias. This phenomenon, known as selfabsorption, is a completely independent process from the attenuation through the sample matrix discussed above. Self-absorption is a difficult SGS measurement issue. Although addressed in the past, ${ }^{6}$ the correction for self-absorption has yet to be adequately implemented and field tested.

It was known that sample (matrix) density and end effects were SGS issues that would affect the present study with the vitrified ash item. The other potential sources of bias were greatly reduced because every attempt was made during the sample preparation to ensure that the matrix was uniform and that the ash was evenly distributed throughout the matrix. Also, the -40 mesh size of the ash precluded that the $\mathrm{Pu}$ would be in lumps. To corroborate this belief, the sample was examined by real time radiography. No evidence (such as dark or light areas or spots) of matrix nonuniformity or Pu clumping was seen. Further, the sample underwent a tomographic gamma scan in order to determine the homogeneity as a function of both radius and height. The resulting density and emission images revealed nothing that would be suspected of impairing the measurement. ${ }^{7}$ End effects, however, were unavoidable because of the small sample height $(\sim 2.6$ inches $)$ in relation to the $1 / 2$-inch and 2 -inch collimator sizes. It 
was also unclear if the transmission (and transmission uncertainty) would be sufficient through $\sim 8$ inches of borosilicate glass matrix having a density of $\sim 2.6 \mathrm{~g} / \mathrm{cm}^{3}$. Initial calculations revealed that the transmission would be $<1 \%$. The validation would be to measure the item, check the transmission (and uncertainties) through the almost opaque region of the matrix, do the end-effects corrections, and compare the final mass results with the baseline result from calorimetry and $\gamma$ isotopics. If the results are not biased low and the uncertainties are reasonable, then it can be assumed that there is little or no Pu lumpiness and/or matrix inhomogeneities and that the transmission is adequate.

\section{SGS Measurement Results and Analysis}

When the sample was received into the NDA Laboratory for the SGS measurements, the overpack (outer container) was opened to check if the inner container was centered and upright. As a result of the inner container being "bagged out" (placed into two polyvinyl chloride bags) from the glove box line, the bags caused it to tilt and lean against the outer container wall. To correct this, paper was stuffed between the inner and outer containers to act as a crude spacer to center and stabilize the inner container. Had that not been done, as the sample was rotated during the data acquisition, the actual item in the inner container would have been wobbling with the result that the transmission source would have seen varying diameters. That would have introduced the equivalent of another end-effects anomaly, this time from the side of the container. ${ }^{5}$ The final SNM result would have then been biased even lower.

As already indicated, the NDA Laboratory has two SGS instruments, one for can-sized items (1/2-inch collimation and segment size) and the other for drums (2-inch). Most of the data in this study, shown in Tables $3 \mathrm{a}$ and $3 \mathrm{~b}$, were acquired on the small-geometry instrument because $1 / 2$-inch collimation is currently available at RFETS and the vitrified ash sample is a can-sized item. However, some data were also obtained on the 2-inch SGS, shown in Table 4, in order to provide a means of cross-comparison with the $1 / 2$-inch results. This proved to be very instructive and lent additional credence to the correctness of the analysis interpretation and results. For example, because of the larger collimation and segment step size of the 2-inch instrument, the final answer should be biased much lower than that of the $1 / 2$-inch if end effects are the primary bias generator. Comparing the results in the "Total SNM" columns in Tables $3 \mathrm{a}$ and 4 , this is indeed seen to be the case. Looking at the "Norm 1" column, which compares the total SNM results to the calorimetry and $\gamma$-isotopics baseline value, the 2 -inch SGS is biased $64 \%$ low compared with $81 \%$ for the $1 / 2$-inch instrument. If the bias due to end effects is computationally corrected, and if the final corrected SNM results from both instruments compare favorably with the baseline value, that will be additional strong evidence that the end-effects corrections are being done properly and that end effects is the primary bias driver. Looking at the results in the "Corrected mass" and "Norm 2" columns of both tables, it is evident that end effects was able to account for all the bias. The fact that the corrected mass from the 2-inch SGS is about $5 \%$ high compared with the $1 / 2$-inch will be explained below. 
Table 3a

Assay Data for SGS with 1/2-inch Collimation

\begin{tabular}{|c|c|c|c|c|c|c|c|c|c|c|}
\hline $\begin{array}{c}\text { Run } \\
\#\end{array}$ & $\begin{array}{c}\text { Total } \\
\text { SNM } \\
(\mathbf{g})\end{array}$ & $\begin{array}{c}\text { Uncer- } \\
\text { tainty } \\
(\mathbf{g})\end{array}$ & $\begin{array}{c}\text { \% } \\
\text { Uncer- } \\
\text { tainty }\end{array}$ & $\begin{array}{c}\text { Offset } \\
\text { (in) }\end{array}$ & $\begin{array}{c}\text { End } \\
\text { effects } \\
(\mathbf{g})\end{array}$ & $\begin{array}{c}\text { \% } \\
\text { Correct- } \\
\text { ion }\end{array}$ & $\begin{array}{c}\text { Corrected } \\
\text { mass } \\
(\mathbf{g})\end{array}$ & $\begin{array}{c}\text { Norm } \\
\mathbf{1}^{\dagger, \oplus}\end{array}$ & $\begin{array}{c}\text { Norm } \\
\mathbf{2}^{\ddagger, \oplus}\end{array}$ & $\begin{array}{c}\text { Count } \\
\text { time } \\
(\mathbf{m i n})\end{array}$ \\
\hline $\mathbf{1}$ & 49.801 & 4.764 & 9.57 & 0.00 & 10.5 & 21.1 & 60.3 & 0.85 & 1.03 & 20 \\
\hline $\mathbf{2}$ & 52.378 & 6.148 & 11.74 & 0.25 & 8.8 & 16.8 & 61.2 & 0.89 & 1.05 & 20 \\
\hline $\mathbf{3}$ & 48.179 & 5.692 & 11.81 & 0.12 & 8.9 & 18.5 & 57.1 & 0.82 & 0.98 & 20 \\
\hline $\mathbf{4}$ & 47.065 & 3.072 & 6.53 & 0.38 & 9.8 & 20.8 & 56.9 & 0.80 & 0.97 & 20 \\
\hline $\mathbf{5}$ & 44.278 & 1.524 & 3.44 & 0.25 & 11.0 & 24.9 & 55.3 & 0.76 & 0.94 & 20 \\
\hline $\mathbf{6}$ & 43.390 & 1.800 & 4.15 & 0.25 & 11.0 & 25.4 & 54.4 & 0.74 & 0.93 & 20 \\
\hline $\mathbf{7}$ & 47.441 & 5.521 & 11.64 & 0.00 & 10.0 & 21.0 & 57.4 & 0.81 & 0.98 & 20 \\
\hline $\mathbf{8}$ & 44.675 & 1.855 & 4.15 & 0.00 & 9.1 & 20.3 & 53.8 & 0.76 & 0.92 & 28 \\
\hline $\mathbf{9}$ & 49.596 & 6.000 & 12.10 & 0.12 & 10.5 & 21.2 & 60.1 & 0.85 & 1.03 & 28 \\
\hline $\mathbf{1 0}$ & 47.362 & 1.537 & 3.24 & 0.00 & 9.5 & 20.1 & 56.9 & 0.81 & 0.97 & 60 \\
\hline Avg & 47.417 & 3.791 & 7.84 & & 9.9 & 21.0 & 57.3 & 0.81 & 0.98 & \\
\hline Std Dev & 2.633 & 1.909 & 3.69 & & 0.8 & 2.4 & 2.4 & 0.04 & 0.04 & \\
\hline
\end{tabular}

${ }^{\dagger}$ Norm 1 is the ratio of the measured total SNM to the characterized sample value of $58.547 \mathrm{~g}$.

$\ddagger$ Norm 2 is the ratio of the end-effects-corrected mass to $58.547 \mathrm{~g}$.

${ }^{\oplus}$ These values can be read as \% accuracy by subtracting 1.00 and multiplying by 100 .

${ }^{8}$ The approximate time counting just the emitted radiation; i.e., not the empty space in the containers.

Data were acquired at different initial vertical displacements to check for any bias dependence on starting position. The starting positions are shown in the "Offset" columns in Tables 3a, 3b, and 4 . The indication from the results is that any bias dependence on offset is less than the assay uncertainty and can be ignored. In addition, by obtaining 4 assays on the 2-inch SGS at successive initial offsets (1/2-inch vertical displacements), it was possible to obtain a set of data whose individual segment information matched very closely with that from the $1 / 2$-inch instrument. To see this, it was necessary to compare the individual segment information such as transmission and emission (uncorrected counts and/or rate). The precision data are included in Table $3 \mathrm{~b}$ to show the comparison of instrument calculated uncertainty with the standard deviation at the one sigma level (an indicator of $\chi^{2}$ ) for replicate data at longer count times.

The end-effects bias was corrected manually since algorithms have not yet been built into the software. To perform the correction, it was first necessary to carefully examine the transmission and uncorrected assay count rates for each segment in the end-effects regions. It was easy from the transmission and emission segment data to identify many of the salient features of the sample such as the container lid, start of the different container thicknesses, start and extent of the actual item, and the bottom of the container. As mentioned already, it was very interesting and instructive to compare the segment data from the 2-inch and $1 / 2$-inch instruments and match these features. The actual item starts and ends where the transmission has fallen to about $1 / 2 \%$. Since the item is 2.6 inches in height, there are roughly 5 to 6 segments of good assay data through this very dense region for the 1/2-inch instrument and only about 1 for the 2 -inch. The end-effects regions comprise about 3 to 4 segments at the top and bottom of the actual item for both instruments. This region is identified at the top of the 
Table 3b

Precision Data for SGS with 1/2-inch Collimation

\begin{tabular}{|c|c|c|c|c|c|c|}
\hline$\underset{\#}{\text { Run }}$ & $\begin{array}{c}\text { Total SNM } \\
\text { (g) }\end{array}$ & $\begin{array}{l}\text { Uncertainty } \\
\text { (g) }\end{array}$ & $\begin{array}{c}\% \\
\text { Uncertainty }\end{array}$ & $\begin{array}{l}\text { Offset } \\
\text { (in) }\end{array}$ & Norm $^{\dagger}$ & $\begin{array}{l}\text { Count } \\
\text { time } \mathrm{e}^{\ddagger} \\
\text { (min) }\end{array}$ \\
\hline \multicolumn{7}{|c|}{ Precision Test 1} \\
\hline 1 & 48.198 & 1.552 & 3.22 & 0.25 & 0.82 & 90 \\
\hline 2 & 47.387 & 1.560 & 3.29 & 0.25 & 0.81 & 90 \\
\hline 3 & 46.080 & 1.260 & 2.73 & 0.25 & 0.79 & 90 \\
\hline 4 & 48.071 & 2.788 & 5.80 & 0.25 & 0.82 & 90 \\
\hline Avg & 47.434 & 1.790 & 3.76 & & 0.81 & \\
\hline Std Dev & \begin{tabular}{|l}
0.840 \\
\end{tabular} & 0.589 & 1.20 & & 0.01 & \\
\hline \multicolumn{7}{|c|}{ Precision Test 2} \\
\hline 1 & 46.716 & 1.433 & 3.07 & 0.00 & 0.80 & 110 \\
\hline 2 & 44.309 & 1.017 & 2.29 & 0.00 & 0.76 & 110 \\
\hline 3 & 44.516 & 0.885 & 1.99 & 0.00 & 0.76 & 110 \\
\hline 4 & 45.376 & 1.028 & 2.27 & 0.00 & 0.78 & 110 \\
\hline 5 & 47.296 & 1.602 & 3.39 & 0.00 & 0.81 & 110 \\
\hline Avg & 45.643 & 1.193 & 2.60 & & 0.78 & \\
\hline Std Dev & 1.184 & 0.275 & 0.53 & & 0.02 & \\
\hline
\end{tabular}

${ }^{\dagger}$ Norm is the ratio of the measured total SNM to the characterized sample value of $58.547 \mathrm{~g}$. These values can be read as \% accuracy by subtracting 1.00 and multiplying by 100 .

‡ The approximate time counting just the emitted radiation; i.e., not the empty space in the containers.

item as starting where the emission data just starts to exhibit counts above background and the transmission is almost $100 \%$, and ending in the item where the transmission is about $1 / 2 \%$. Therefore, in 3 to 4 segments, the transmission has gradually fallen from almost $100 \%$ to $1 / 2 \%$. The region is identified at the bottom of the item in a similar manner. The procedure is identical with the 2-inch instrument, except that there is only about 1 segment of good assay data in the almost opaque (very dense) region.

Once the end-effects regions have been identified, the correction can be done. First, the partial corrections for each segment in the end-effects regions must be subtracted from the emission data segment by segment. The proper correction is then applied from an average of the correction factors for attenuation ${ }^{4}$ in the almost opaque region. These correction factors are easily obtained since they are printed with the segment data. The resulting additional corrected count rate is then added to the original and the ratio gives the percentage correction, which is shown as "\% Correction" in tables $3 \mathrm{a}$ and 4 . This \% correction factor is used to correct the mass for that assay. 
Table 4

Assay Data for SGS with 2-inch Collimation

\begin{tabular}{|c|c|c|c|c|c|c|c|c|c|c|}
\hline $\begin{array}{c}\text { Run } \\
\#\end{array}$ & $\begin{array}{c}\text { Total } \\
\text { SNM } \\
(\mathbf{g})\end{array}$ & $\begin{array}{c}\text { Uncer- } \\
\text { tainty } \\
(\mathbf{g})\end{array}$ & $\begin{array}{c}\text { \% } \\
\text { Uncer- } \\
\text { tainty }\end{array}$ & $\begin{array}{c}\text { Offset } \\
\text { (in) }\end{array}$ & $\begin{array}{c}\text { End } \\
\text { effects } \\
(\mathbf{g})\end{array}$ & $\begin{array}{c}\text { \% } \\
\text { Correct- } \\
\text { ion }\end{array}$ & $\begin{array}{c}\text { Corrected } \\
\text { mass } \\
(\mathbf{g})\end{array}$ & $\begin{array}{c}\text { Norm } \\
\mathbf{1}^{\dagger, \oplus}\end{array}$ & $\begin{array}{c}\text { Norm } \\
\mathbf{2}^{\ddagger, \oplus}\end{array}$ & $\begin{array}{c}\text { Count } \\
\text { time } \\
(\mathbf{m i n})\end{array}$ \\
\hline & & & & & & & & & & \\
\hline $\mathbf{1}$ & 37.362 & 3.817 & 10.22 & 1.50 & 23.3 & 62.5 & 60.7 & 0.64 & 1.04 & 7 \\
\hline $\mathbf{2}$ & 40.963 & 4.196 & 10.24 & 1.00 & 21.9 & 53.6 & 62.9 & 0.70 & 1.07 & 7 \\
\hline $\mathbf{3}$ & 33.876 & 3.480 & 10.27 & 0.50 & 25.9 & 76.3 & 59.7 & 0.58 & 1.02 & 7 \\
\hline $\mathbf{4}$ & 37.298 & 3.817 & 10.23 & 0.00 & 25.1 & 67.2 & 62.4 & 0.64 & 1.07 & 7 \\
\hline Avg & 37.375 & 3.828 & 10.24 & & 24.1 & 64.9 & 61.4 & 0.64 & 1.05 & \\
\hline Std Dev & 2.506 & 0.253 & 0.02 & & 1.5 & 8.2 & 1.3 & 0.04 & 0.02 & \\
\hline
\end{tabular}

${ }^{\dagger}$ Norm 1 is the ratio of the measured total SNM to the characterized sample value of $58.547 \mathrm{~g}$.

${ }^{\ddagger}$ Norm 2 is the ratio of the end-effects-corrected mass to $58.547 \mathrm{~g}$.

${ }^{\oplus}$ These values can be read as \% accuracy by subtracting 1.00 and multiplying by 100 .

\$ The approximate time counting just the emitted radiation; i.e., not the empty space in the containers.

It should be noted that any bias built into the original mass calculation, for example, through the calibration, will remain in the answer after the end-effects bias is removed. For example, the $5 \%$ high bias seen in the "Norm 2" column in Table 4 can be easily explained. Both the 2inch and 1/2-inch SGSs were calibrated on a set of 2 -liter plutonium can standards. ${ }^{8}$ The can standards are uniform mixtures of $\mathrm{PuO}_{2}$ and diatomaceous earth in 3.75-inch diameter by 10.75 -inch high stainless steel inner cans. Since these standards are filled to a height of only 7 inches, it is very likely that the 2-inch SGS would experience end effects on the order of $5 \%$. This $5 \%$ bias is then built into the calibration and is propagated whenever that calibration is used. End effects for the 1/2-inch instrument are negligible on the 7-inch standards.

\section{TNC Measurement Results}

Data were acquired on a drum-sized TNC to determine if that technique could be employed as a fallback in case the SGS, for whatever reason, was not viable. The data are presented in Table 5. It is apparent from the "Norm" column that there is a $16 \%$ high (see 1.16) bias" with a rather large standard deviation. In addition, from TNC counting experience, the data also exhibit a much higher than normal ratio of "Totals Rate" to "Reals Rate" (about a factor of 10 high). This information, coupled with the high levels of impurities in the sample as evident in Table 1 (especially the large weight percentages of the chloride and fluoride components), points to $(\alpha, n)$ reactions as being the probable cause of the bias.

\footnotetext{
This value may be high because the TNC was found to be $6 \%$ high for the runs performed on March 3 . The TNC was recalibrated on March 4.

\# Totals represent single neutron events. Reals represent multi-neutron, plutonium fission events, which directly correspond to the mass.
} 
Table 5

Thermal Neutron Counter Data

\begin{tabular}{|c|c|c|c|c|c|c|c|c|c|}
\hline $\begin{array}{c}\text { Run } \\
\#\end{array}$ & $\begin{array}{c}\text { Total } \\
\text { SNM } \\
(\mathbf{g})\end{array}$ & $\begin{array}{c}\text { Uncer- } \\
\text { tainty } \\
(\mathbf{g})\end{array}$ & $\begin{array}{c}\% \\
\text { Uncer- } \\
\text { tainty }\end{array}$ & Norm $^{\dagger}$ & $\begin{array}{c}\text { Totals } \\
\text { Rate } \\
\text { (cts/s) }\end{array}$ & $\begin{array}{c}\text { Reals } \\
\text { Rate } \\
\text { (cts/s) }\end{array}$ & $\begin{array}{c}\text { Count } \\
\text { time } \\
\text { (min) }\end{array}$ & Date & Time \\
\hline $\mathbf{1}$ & 78.994 & 8.909 & 11.28 & 1.35 & 27701 & 87 & 30 & 3-Mar-97 & $13: 58$ \\
\hline $\mathbf{2}$ & 77.994 & 8.880 & 11.39 & 1.33 & 27532 & 86 & 30 & 3 -Mar-97 & $17: 11$ \\
\hline $\mathbf{3}$ & 63.424 & 9.382 & 14.79 & 1.08 & 27888 & 68 & 30 & 5 -Mar-97 & $17: 17$ \\
\hline $\mathbf{4}$ & 57.463 & 9.605 & 16.71 & 0.98 & 26412 & 63 & 30 & 20 -Mar-97 & $14: 31$ \\
\hline $\mathbf{5}$ & 62.096 & 10.044 & 16.17 & 1.06 & 28113 & 68 & 30 & 20 -Mar-97 & $16: 19$ \\
\hline Avg & 67.994 & 9.364 & 14.07 & 1.16 & 27529 & 74 & & & \\
\hline Std Dev & 8.804 & 0.439 & 2.32 & 0.15 & 591 & 10 & & & \\
\hline
\end{tabular}

${ }^{\dagger}$ Norm is the ratio of the measured total SNM to the characterized sample value of $58.547 \mathrm{~g}$. These values can be read as \% accuracy by subtracting 1.00 and multiplying by 100 .

If the coincidence rate in the TNC is enhanced by induced fissions resulting from $(\alpha, n)$ reactions due to the high levels of impurities in the sample, then the enhanced coincidence rate can be corrected if the neutron multiplication is known. The multiplication can be estimated from Monte Carlo calculations. From the preliminary data here, the bias appears to be about $15 \%$ to $20 \%$ from the induced multiplication. How well the correction can be done from Monte Carlo is difficult to estimate, but $3 \%$ to $5 \%$ is probably reasonable. ${ }^{10}$

\section{CONCLUSIONS AND RECOMMENDATIONS}

The results presented in this report show that the $1 / 2$-inch SGS can achieve an accuracy well within the RFETS $10 \%$ target using counting times of less than 30 minutes. The only measurement problem encountered was a bias caused by end effects due to the small sample height of 2.6 inches. The sample preparation and detailed measurement information are included in this document. The overall accuracy results for all NDA techniques (relative to calorimetry and $\gamma$-ray isotopics) are shown in the following table:

Table 6

Compilation of Accuracy Results for NDA Study

\begin{tabular}{|c|c|c|}
\hline & $\begin{array}{c}\text { Avg. Accuracy } \\
(\%)\end{array}$ & $\begin{array}{c}\text { Rel. Std. Dev. } \\
(\%)\end{array}$ \\
\hline 1/2-inch SGS & -2 & 4 \\
\hline 2-inch SGS & +5 & 2 \\
\hline TNC $^{\dagger}$ & +16 & 15 \\
\hline
\end{tabular}

${ }^{\dagger}$ Results uncorrected for $(\alpha, n)$ bias.

computer model used for statistical modeling of complex processes such as neutron transport simulation 
The bias caused by end effects can be addressed several ways. First, if the height of the samples at RFETS is 2 or more times that of the 2.6-inch sample in this study, then the end effects will probably be negligible. However, this should be verified by a careful examination of the data as detailed in this report. Second, if end effects are not negligible, but if one or more of the samples can be used as calibration standards, then the bias will be a non-issue since it will be built into the calibration. This presupposes that items to be measured in the future are very similar to these standards. Any items differing from the standards would have to be investigated separately. Finally, if necessary, the corrections can always be done by hand as demonstrated in this report. It may be that, with enough similar items, certain universal correction values could be employed on the majority of samples, coupled with periodic verification on samples at a statistically determined frequency. End-effects algorithms could probably be implemented into the SGS software without too much effort.

The use of an agglomerated waste form should not present any NDA concerns for the SGS. In fact, assuming the ash continues to be distributed rather uniformly throughout the matrix, SGS accuracy and precision should actually improve compared to the fully-melted waste form used in this study. This improvement is related to the fact that the agglomeration process only adheres the individual frit beads at their surface, leaving significant air gaps between the beads. This produces a waste form that has both lower density and greater height. Lower density will allow higher transmission through the waste form, which yields a higher count rate and improved precision. The greater height will increase accuracy because the fraction of segments affected by end effects will be much smaller than for a sample with less height. As a fallback to replace the SGS should that need ever arise, a drum-sized TNC was investigated. The preliminary results looked very encouraging. A bias was noted, however, and attributed to $(\alpha, n)$ reactions on some of the many impurities in the sample. Although, in principle, this could easily be corrected to well within the $10 \%$ accuracy requirement using Monte Carlo calculations, the results weren't presented here since the correction was done on only one measurement as a test case. Again, if a calibration could be done on one or more sample standard items, the bias would not be an issue.

Finally, it seems rather ironic that the measurement results from the 2-inch SGS turned out so well. This can probably be attributed to a statistical anomaly of the limited data. However, the fact that the sample was very homogeneous, ideal for an SGS, probably played a large part. In any case, since there is only one segment of good data per assay, the $1 / 2$-inch collimation and step size is certainly to be preferred. 


\section{REFERENCES}

1. T. Ricketts, Los Alamos National Laboratory memorandum, NMT-2:FY97-(info to follow).

2. D. Reilly, N. Ensslin, H. Smith, Jr., and S. Kreiner, eds., Passive Nondestructive Assay of Nuclear Materials (Washington, D.C. Government Printing Office, 1991), United States Nuclear Regulatory Commission NUREG/CR-5550, March 1991, pp. 617-660.

3. D. Reilly, et al., pp. 65-194; E. R. Martin, D.F. Jones, and J.L. Parker, "Gamma-Ray Measurements with the Segmented Gamma Scan," Los Alamos National Laboratory Manual LA-7059-M, December 1977.

4. D. Reilly, et al., pp. 159-194; J. L. Parker, "The Use of Calibration Standards and the Correction for Sample Self-Attenuation in Gamma-Ray Nondestructive Assay," Los Alamos National Laboratory Report LA-10045, Rev., (August 1984).

5. J. R. Hurd, S. M. Long, and T. E. Sampson, "Bias Investigation of a 55-Gallon DrumSized Segmented Gamma Scanner," Nuclear Materials Management Vol. XXII (Proc. Issue) 675-681 (1993).

6. T. H. Prettyman, J. K. Sprinkle, Jr., and G. A. Sheppard, "A Weighted Least-Squares Lump Correction Algorithm for Transmission-Corrected Gamma-Ray Nondestructive Assay," Nuclear Materials Management Vol. XXII (Proc. Issue) 682-690 (1993).

7. Thomas H. Prettyman and David J. Mercer, Los Alamos National Laboratory, private communication.

8. S.-T. Hsue, S.M. Simmonds, V.L. Longmire, and S.M. Long, "Design and Fabrication of SGS Plutonium Standards," Proceedings of the Fourth International Conference on Facility Operations-Safeguards Interface, Sept. 29-Oct. 4, 1991, p. 410.

9. D. Reilly et al., pp. 457-528; Merlyn S. Krick and Howard O. Menlove, "The High-Level Neutron Coincidence Counter (HLNCC): Users' Manual," Los Alamos National Laboratory Manual LA-7779-M, June, 1977.

10. Merlyn S. Krick, Los Alamos National Laboratory, private communication. 
APPENDIX A

Composition of Iron Borosilicate Frit

\begin{tabular}{|c|c|c|c|}
\hline Component & Weight Percent & Component & Weight Percent \\
\hline $\mathrm{Al}_{2} \mathbf{O}_{3}$ & 2.95 & $\mathrm{MoO}_{3}$ & 0.28 \\
\hline $\mathbf{B}_{2} \mathbf{O}_{3}$ & 10.29 & $\mathrm{Na}_{2} \mathrm{O}$ & 11.25 \\
\hline $\mathrm{BaO}_{\mathrm{CaO}}$ & 0.35 & $\mathrm{Nd}_{2} \mathrm{O}_{3}$ & 0.67 \\
\hline $\mathrm{CO}_{2} \mathbf{O}_{3}$ & 0.69 & $\mathrm{NiO}$ & 0.68 \\
\hline $\mathrm{Cr}_{\mathbf{2}} \mathbf{O}_{3}$ & 0.05 & $\mathrm{PbO}$ & 1.75 \\
\hline $\mathrm{CuO} \mathbf{O}$ & $\mathrm{P}_{2} \mathrm{O}_{5}$ & 0.31 \\
\hline $\mathrm{Fe}_{2} \mathbf{O}_{3}$ & 0.10 & $\mathrm{SO}_{3}$ & 0.73 \\
\hline $\mathrm{K}_{2} \mathbf{O}$ & 0.20 & $\mathrm{SiO}_{2}$ & 49.35 \\
\hline $\mathrm{La}_{2} \mathbf{O}_{3}$ & 5.80 & $\mathrm{SrO}_{3}$ & 0.01 \\
\hline $\mathrm{Li}_{2} \mathbf{O}$ & 0.87 & $\mathrm{TiO}_{2}$ & 0.14 \\
\hline $\mathrm{MgO}$ & 1.94 & $\mathrm{Y}_{2} \mathrm{O}_{3}$ & 0.01 \\
\hline $\mathbf{M n O}$ & 3.14 & $\mathrm{ZnO}_{3}$ & 0.49 \\
\hline & 0.72 & $\mathrm{ZrO}_{2}$ & 3.93 \\
\hline
\end{tabular}




\section{APPENDIX B}

1. The baseline SNM content of the ash item was established using a calorimeter and gamma isotopic analysis.

2. The ash was introduced into the glove box and inspected for consistency of the particle size. The ash was found to be in a finely-divided state and easily passed through a 40-mesh screen.

3. The ash was placed in a V-blender and blended for 30 minutes to ensure homogeneity. The ash was removed and placed in a separate storage container.

4. Ash and frit in the amounts of 612.2 grams and 5250.0 grams, respectively, were placed in the V-blender and blended for 10 minutes to ensure homogeneity.

5. The mixture was removed from the V-blender and placed in the modified Vollrath 88080 stainless steel can.

6. The container with frit and ash was placed inside the muffle furnace. The combined height of the frit and ash in the container was 5 inches. A thermocouple was placed inside the container so that it was $\sim 1-2$ inches from the bottom.

7. The sample was heated according to the following temperature profile. The times represent the length of time required to reach the target temperature.

\begin{tabular}{|c|c|}
\hline Temp $\left({ }^{\circ} \mathrm{C}\right)$ & Time (h) \\
\hline 75 & 0 \\
\hline 300 & 2 \\
\hline 600 & 10 \\
\hline 800 & 3 \\
\hline 900 & 3 \\
\hline 1000 & 2 \\
\hline 1000 & 2 (soak) \\
\hline
\end{tabular}

8. The furnace power was turned off, and the container was left to cool overnight with the furnace door closed. The material temperature profile during cool-down was as follows:

\begin{tabular}{|c|c|}
\hline Temp $\left({ }^{\circ} \mathrm{C}\right)$ & Time $(\mathrm{h})$ \\
\hline 1008 & 0 \\
\hline 832 & 1 \\
\hline 664 & 2 \\
\hline 543 & 3 \\
\hline 461 & 4 \\
\hline 53 & 18 \\
\hline
\end{tabular}


9. After the temperature dropped to a level where the item could be handled $\left(<60^{\circ} \mathrm{C}\right)$, the junction box from the thermocouple was cut and the can was removed from the muffle furnace. The remaining thermocouple was cut as close as possible to the surface of the glass.

10. The can was bagged out of the glove box, placed in a steel overpack container, and submitted for the NDA study. 